\title{
A Cross Sectional Sero-Study of Verocytotoxigenic Escherichia coli (VTEC) Serotypes in Apparently Healthy and Diarrhoeic Cattle in Abuja, Federal Capital Territory (FCT), Nigeria
}

\author{
Simon Ikechukwu Enem ${ }^{1}$, Stephen Ike Oboegbulem², Chinwe Elizabeth Okoli ${ }^{1}$, \\ Enid Ene Godwin'1 \\ ${ }^{1}$ Department of Veterinary Public Health \& Preventive Medicine, University of Abuja, Abuja, Nigeria \\ ${ }^{2}$ Department of Veterinary Public Health \& Preventive Medicine, University of Nigeria, Nsukka, Nigeria \\ Email: "enemsimon@yahoo.com
}

Received 21 May 2016; accepted 18 June 2016; published 21 June 2016

Copyright (C) 2016 by authors and Scientific Research Publishing Inc.

This work is licensed under the Creative Commons Attribution International License (CC BY). http://creativecommons.org/licenses/by/4.0/

\section{c) (i) Open Access}

\begin{abstract}
It is reckoned worldwide that verocytotoxigenic Escherichia coli (VTEC) serotypes are important food borne pathogens causing severe health problems in humans. A cross sectional epidemiological study was carried out to determine the prevalence of VTEC serotypes (0157 and non 0157) in both apparently healthy and diarrhoeic cattle in Abuja, FCT. A total of 718 faecal samples collected from abattoirs and cattle herds from Abuja, FCT representing 381 from apparently healthy and 337 from diarrhoeic cattle were analyzed. Primary isolation of typical $E$. coli was done using Eosin Methylene Blue (EMB) agar and performing biochemical tests. Samples were further analyzed using Cefixime, Tellurite-Sorbitol McConkey (CT-SMAC) agar to identify sorbitol and non sorbitol fermenting E. coli. Further characterization of both the sorbitol fermenting and non sorbitol fermenting $E$. coli was done using commercially procured latex agglutination test kits from Oxoid, United Kingdom. The prevalence of VTEC 0157 in apparently healthy cattle was $1.84 \%$ and $2.96 \%$ for diarrhoeic cattle while the prevalence of non 0157 VTEC was $3.67 \%$ and $7.12 \%$ for apparently healthy and diarrhoeic cattle respectively. There was no strong association $(p>0.05)$ between faecal consistency and infection with VTEC 0157. A strong association $(p<0.05)$ however existed between faecal consistency and infection with non-0157 VTEC. Diarrhoeic cattle appear likely to be more affected. The implication of the study is that individuals in contact with cattle such as veterinarians, abattoir workers and cattle herdsmen are at risk of exposure to VTEC and proper hygienic control measures should be adopted.
\end{abstract}

\footnotetext{
${ }^{*}$ Corresponding author.
} 


\section{Keywords}

\section{Sero-Study, VTEC Serotypes, Apparently Healthy, Diarrhoeic, Cattle}

\section{Introduction}

Verocytotoxigenic Escherichia coli are highly significant zoonotic threat to public health globally. The serogroup $\mathrm{O} 157$ is particularly important and recently non O157 serogroups namely, O26, O111, O103 and O45 have emerged and been associated with severe food borne illness in humans [1]. A study in Irish cattle showed that while VTEC O157 are being carried by cattle presented for slaughter in Ireland, a number of other verotoxin producing strains such as O26, O111, O103 and O145 are beginning to emerge [2].

Food borne spread of VTEC infection usually results from well recognized lapses in food handling, notably failure to achieve adequate cooking temperatures [3] [4] or contamination of ready-to-eat products [5]. Their low infective dose combined with the severity of symptoms associated with the infection make them a significant concern [1], poses an occupational risk to caterers and others who handle food, mainly because of its low infective dose [6].

VTEC rarely cause disease in animals and ruminants are recognized as their main natural reservouir [7] [8]. Cattle are considered to be the major animal source of VTEC that are virulent to humans and the ecology of this microorganism in cattle farming has been extensively studied [9]. Harbouring of E. coli O157 in cattle is a significant concern for public health because of their transmitting capability to humans through contaminated foods and water with faeces from cattle [10] [11]. Monitoring of ruminants is essential to evaluate risk factors associated with VTEC infection in humans. Faeces, hides, and pre-chilled carcasses are the best samples to monitor VTEC at slaughter and to compare data among countries [12].

Although, E. coli O157 is the most renowned VTEC, other serogroups, including O26, O111, O103, O145 and O121 have the potential to cause serious human illness [13] [14]. Six non-O157 groups have been identified by the Centre for Disease Prevention and Control [15] as being responsible for over 70\% of non-O157 VTECassociated illness (O26, O45, O103, O111, O121 and O145) [16]. A prevalence of VTEC O157, O26, O111 and "O not determined (OND)" as 6.3, 3.8, 0.6 and 2.5 percent respectively was also reported [17]. Unlike O157 VTEC, some non O157 VTEC such as O5, O26, O111 and O118 can be isolated from calves with diarrhea [18] [19].

The aim of this study was to assess the prevalence of VTEC O157 and non-O157 serotypes in apparently healthy and diarrhoeic cattle in Abuja, FCT with the view to raising awareness amongst population at risk to fashion out creative hygienic means of controlling the infection.

\section{Materials and Methods}

A cross sectional epidemiological study was used in this research which was carried out between May, 2011 and April, 2012. Faecal samples were collected from 718 cattle in selected cattle herds (5) and slaughter houses (3) in Abuja, FCT. Of that number, 381 were collected from apparently healthy cattle while 337 faecal samples were from diarrhoeic cattle. Among the cattle herds selected, 137 were calves (less than one year old) while 221 were adults. All the samples collected from abattoir were from adults as calves were not routinely slaughtered in abattoirs. Faecal samples were collected from freshly voided faeces to identify and differentiate the diarrhoic from the apparently healthy. It is reported that isolation rates may be improved by taking voided faecal samples in preference to rectal swabs [20].

Samples (about $0.5 \mathrm{~g}$ in each case) were first inoculated into $5 \mathrm{ml}$ of an enriched media (Buffered Peptone Water supplemented with $8 \mathrm{mg} / \mathrm{l}$ vancomycin, $10 \mathrm{mg} / \mathrm{l}$ cefsulodin and $0.05 \mathrm{mg} / \mathrm{l}$ cefixine (BPW-VCC) and incubated for $37^{\circ} \mathrm{C}$ for 6 - 8 hrs [21] to suppress the growth of gram positive organisms. Confirmed E. coli samples showing typical greenish sheen colouration when cultured into eosin methylene blue (EMB) agar were subcultured into cifixine - tellurite sorbitol McConkey (CT_SMAC) agar. The non sorbitol fermenters (NSF) and the sorbitol fermenters (SF) were further characterized using latex agglutination test kits obtained from Oxoid ltd, Hampshire, UK. The test kits were used according to the specifications of the manufacturers. 


\section{Results}

Faecal samples were collected from both cattle herds and slaughter houses. Of the 358 samples analyzed from cattle herds, 207 were from apparently healthy while 151 were from diarrhoeic cattle. Of the 360 samples from slaughter cattle, 174 were from apparently healthy while 186 were from diarrhoeic cattle (Table 1). The prevalence of VTEC O157 is 1.84 in and 2.96 in apparently healthy and diarrhoeic cattle respectively (Table 2) while the prevalence of VTEC non $\mathrm{O} 157$ was $3.67 \%$ and $7.12 \%$ in apparently healthy and diarrhoeic cattle respectively (Table 3). The specific prevalence for the non O157 VTEC isolated from cattle in FCT was determined and the prevalence for O26 was highest (Table 4). The "O" not determined ("O"ND) represents the serotypes that were not typed in this research due to unavailability of the serocheck agglutination test kits specific to them.

Pearson's chi square was used to analyze the significance of the faecal consistency to the infection with both VTEC 0157 and non-O157 VTEC. There was no strong association $(\mathrm{p}>0.05)$ between faecal consistency and infection with VTEC O157. A strong association $(\mathrm{p}<0.05)$ however existed between faecal consistency and infection with non-O157 VTEC. Diarrhoeic cattle appear likely to be more affected.

\section{Discussion}

Verocytotoxigenic Escherichia coli (VTEC) have become a very important and world-wide reported food-borne pathogen. In this study, an assessment of the prevalence of VTEC O157 and non O157 serotypes were carried out and the result indicated prevalence for VTEC O157 of 1.84\% and $2.96 \%$ for apparently healthy and diarrhoeic cattle respectively. The prevalence for non O157 VTEC was 3.67\% and 7.12\% for apparently healthy and diarrhoeic cattle respectively. The result of the finding is closely related to other findings reported in published literatures [22]-[24].

Table 1. Sample collection analysis.

\begin{tabular}{cccc}
\hline Subject & No collected & Apparently healthy & Diarrhoeic \\
\hline Cattle herds & 358 & 207 & 151 \\
Slaughter cattle & 360 & 174 & 186 \\
Total & 718 & 381 & 337 \\
\hline
\end{tabular}

Table 2. Prevalence of VTEC O157 in Apparently Healthy and Diarrhoreic cattle.

\begin{tabular}{cccc}
\hline Type cattle & No tested & No positive & \% positive \\
\hline Apparently Healthy & 381 & 7 & 1.84 \\
Diarrhoeic cattle & 337 & 10 & 2 \\
\hline
\end{tabular}

$(\mathrm{p}>0.05)$.

Table 3. Prevalence of VTEC non O157 in Apparently Healthy and Diarrhoreic cattle.

\begin{tabular}{cccc}
\hline Type cattle & No tested & No positive & \% positive \\
\hline Apparently Healthy & 381 & 14 & 3.67 \\
Diarrhoeic cattle & 337 & 24 & 7.12 \\
\hline
\end{tabular}

$(\mathrm{p}<0.05)$.

Table 4. Specific prevalence of non O157 VTEC in apparently healthy and diarrhoeic cattle.

\begin{tabular}{cccccccccc}
\hline Subject & No collected & \% positive & O26 & O10 & O145 & O111 & O91 & “O”ND \\
\hline Apparently Healthy & 381 & 14 & 3 & 2 & 3 & 2 & 1 & 3 \\
Diaorrhoeic & 337 & 24 & 7 & 5 & 4 & 1 & 2 & 5 & 3 \\
Total & 718 & 38 & 10 & 7 & 7 & 3 & 3 & 0.42 & 1.11 \\
Prevalence \% & & 5.25 & 1.31 & 0.97 & 0.97 & 0.42 \\
\hline
\end{tabular}


A wide range of prevalence estimates ranging from $0.1 \%$ to $62 \%$ of E. coli $\mathrm{O} 157$ in cattle was reported worldwide [10] [11] [25]. Bonardi [17] reported a prevalence of VTEC O157, O26, O111 and "O” not determined as $6.3 \%, 3.8 \%, 0.6 \%$ and $2.5 \%$ respectively. A study in Irish cattle showed that while VTEC O157 are being carried by cattle presented for slaughter in Ireland, a number of other verotoxin producing strains such as O26, O111, O103, O145 are beginning to emerge [2]. Roopnarine [26] detected by dry spot test E. coli isolates with prevalence of 2.2\%, 2.2\%, 4.4\% and 6.7\% belonging to non O157 strains O91, O111, O103 and O157 respectively.

In this study, the specific non O157 VTEC isolated were O26 (1.31\%), O’ND (1.11\%), O103 (0.97\%), O145 (0.97\%), O111 (0.42\%) and O91 (0.42\%) in the descending order of number of isolation. Brooks [27] in a twenty year study in USA, confirmed the importance of non O157 VTEC strain in human infection pointing out that the most common were O26 (22\%), O111 (16\%), O103 (12\%), O121 (8\%), O45 (7\%) and O145 (5\%). EFSA, [12] reported that a restricted range of serotypes (i.e. O26, O103, O91, O145 and O111) are associated with public health. Bettelheim, [28] stated that O26 VTEC should be considered as pathogen for both cattle and humans being isolated from sick and healthy cattle (ratio 4:3) as well as sick and healthy people (ratio 76:3).

The percentage of positive isolates in diarrhoeic cattle exceeded that of apparently healthy in this study. For VTEC 0157, diarrhoeic was $2.97 \%$ as against the $1.84 \%$ for apparently healthy. Also, for non O157 VTEC, diarrhoeic was $7.12 \%$ as against the $3.67 \%$ for apparently healthy. Sanz [29] recovered VTEC strains from 10 (23\%) of 43 calves with diarrhea, from 24 (29\%) of 83 healthy calves, from 40 (44\%) of 91 healthy cows waiting at the slaughter house and from 6 (22\%) of healthy grazing cattle. Mohammad [30] reported the isolation from cattle and buffalo calf diarrhea, serotypes of verocytotoxigenic E. coli strains.

\section{Conclusion}

The assessment of the prevalence of VTEC O157 and non O157 serotypes in cattle herds and abattoirs in Abuja, FCT showed that both apparently healthy and diarrhoeic cattle carry the organism in certain degrees. Population at risk (abattoir workers, butchers, cattle herdsmen, veterinarians) should adopt proper hygienic and safety measures to tackle the problem of VTEC infection in cattle in the capital territory. Diorrhoeic cattle should be treated before presenting them for slaughter to prevent spread of VTEC and other infections. Farmers' awareness campaign should be raised on the public health implication of VTEC infection.

\section{References}

[1] Duffy, G., Burgess, C.M. and Bolton, J. (2014) A Review of Factors That Affect the Transmission and Survival of Verocytotoxigenic Escherichia coli in the European Farm to Fork Chain. Meat Science, 97, 375-383. http://dx.doi.org/10.1016/j.meatsci.2014.01.009

[2] Thomas, K.M., McCann, M.S., Collery, M.M., Logan, A., Whyte, P., McDowell, D.A. and Duffy, G. (2012) Tracking Verocytotoxigenic Escherichia coli O157, O26, O111, O103 and O145 in Irish Cattle. International Journal of Food Microbiology, 153, 288-296. http://dx.doi.org/10.1016/j.ijfoodmicro.2011.11.012

[3] Heuvalink, A.E., Bluemink, B., van den Biggelaar, F.L.A.M., te Giffel, M.C., Beumer, R.R. and de Boer, E. (1998) Occurrence and Survival of Verocytotoxin-Producing Escherichia coli O157 in Raw Cow's Milk in the Netherlands. Journal of Food Protection, 61, 1597-1601.

[4] Cizek, A., Alexa, P., Literak, I., Hamrik, J. and Smola, J. (1999) Shiga Toxin-Producing Escherichia coli O157 in Feedlot Cattle and Norwegian Rats from a Large-Scale Farm. Letters in Applied Microbiology, 28, 435-439. http://dx.doi.org/10.1046/j.1365-2672.1999.00549.x

[5] Scheutz, F., Beutin, L., Pierard, D. and Smith, H. (2001) Appendix-Nomenclature of Verocytotoxins. In: Duffy, G., Garvey, P. and McDowell, D., Eds., Verocytoxigenic E. coli, Food and Nutrition Press, Inc., Connecticut, 447-452.

[6] Maule, A. (2000) Survival of Verototoxingenic Escherichia coli O157 in Soil, Water and on Surfaces. Symposium Series for Society of Applied Microbiology, 29, 715-785.

[7] Chapman, P.A., Siddons, C.A., Cerdan Malo, A.T. and Harkin, M.A. (1997) A 1-Year Study of Escherichia coli O157 in Cattle, Sheep, Pigs and Poultry. Epidemiology \& Infection, 119, 245-250. http://dx.doi.org/10.1017/S0950268897007826

[8] Blanco, M., Blanco, J.E., Mora, A., Rey, J., Alonso, J.M., Hermoso, M., Hermoso, J., Alonso, M.P., Dahbi, G., Gonzalez, E.A., Bernadez, M.I. and Blanco, J. (2003) Serotype Virulence Genes and Intimin Types of Shigatoxin (Verotoxin) Producing Escherichia coli Isolates from Healthy Sheep in Spain. Journal of Clinical Microbiology, 41, 13511356. http://dx.doi.org/10.1128/JCM.41.4.1351-1356.2003 
[9] Caprioli, A., Morabito, S., Brugere, H. and Oswald, E. (2005) Enterohaemorrhagic Escherichia coli Emerging Issues on Virulence and Modes of Transmission. Veterinary Research, 36, 289-311. http://dx.doi.org/10.1051/vetres:2005002

[10] Mead, P.S. and Griffin, P.M. (1998) Escherichia coli O157:H7. The Lancet, 352, 1207-1212. http://dx.doi.org/10.1016/S0140-6736(98)01267-7

[11] Cooley, M., Carychao, D., Crawford-Miksza, L., Jay, M.T. and Myers, C. (2007) Incidence and Tracking of Escherichia coli O157:H7 in a Major Produce Production Region in California. PLoS ONE, 2, E1159. http://dx.doi.org/10.1371/journal.pone.0001159

[12] European Food Safety Authority (EFSA) (2007) Scientific Opinion of the Panel on Biological Hazards on a Request from EFSA on Monitoring of Verotoxigenic Escherichia coli (VTEC) and Identification of Human Pathogenic VTEC Types. The EFSA Journal, 579, 1-61.

[13] Bonnet, R., Souweine, S., Gauthier, G., Rich, C., Livrelli, V., Sirot, J., Joly, B. and Forestier, C. (1998) Non-O157:H7 Stx2-Producing Escherichia coli Strains Associated with Sporadic Cases of Haemolytic Uremic Syndrome in Adults. Journal of Clinical Microbiology, 36, 1777-1780.

[14] Caprioli, A., Tozzi, A.E., Rizzoni, G. and Karch, H. (1997) Non-O157 Shiga Toxin-Producing Escherichia coli Infections in Europe. Emerging Infectious Diseases, 3, 578-579. http://dx.doi.org/10.3201/eid0304.970425

[15] Centre for Disease Control (CDC) (2010) Two Multistate Outbreaks of Shiga Toxin Producing Escherichia coli Infections Linked to Beef from a Single Slaughter Facility_United States, 2008. Morbidity and Mortality Weekly Report, 59, 557-580.

[16] Bosilevac, J.M. and Koohmaraie, M. (2011) Prevalence and Characterization of Non-O157 Shiga Toxin-Producing Escherichia coli Isolated from Commercial Ground Beef in the United States. Applied and Environmental Microbiology, 77, 2103-2112. http://dx.doi.org/10.1128/AEM.02833-10

[17] Bonardi, S., Alpigiani, I., Tozzoli, R., Vismara, A., Zecca, V., Greppi, C., Bacci, C., Bruini, I. and Brindani, F. (2015) Shiga Toxin-Producing Escherichia coli O157, O26 and O111 in Cattle Faeces and Hides in Italy. Veterinary Record Open, 2, e000061. http://dx.doi.org/10.1136/vetreco-2014-000061

[18] Dorn, C.R., Francis, D.H., Angrich, E.J., Willgohs, J.A., Wilson, R.A., Collins, J.E., Jenke, B.H. and Shawd, S.J. (1993) Characteristics of Vero Cytotoxin Producing Escherichia coli Associated with Intestinal Colonization and Diarrhea in Calves. Veterinary Microbiology, 36, 149-159. http://dx.doi.org/10.1016/0378-1135(93)90136-U

[19] Weiler, L.H., Veiler, E., Erpenstein, C., Schlapp, T., Steinruck, H., Bauerfeind, R., Byomd, A. and Balier, G. (1996) Shiga Toxin Producing Escherichia coli Strains from Bovines: Association of Adhesion with Carriage of Eae and Other Genes. Journal of Clinical Microbiology, 34, 2980-2984.

[20] OIE Terrestrial Manual (2008) Verocytotoxigenic Escherichia coli. www.cfsph.iastate.edu/IICAB/

[21] Pritchard, G.C., Williamson, S., Carson, T., Bailey, J.R., Warner, I., Willshaw, G. and Cheasty, T. (2001) Wild Rabbits: A Novel Vector for Verocytotoxigenic Escherichia coli O157. Veterinary Record, 149, 567.

[22] Pearce, M.C., Evans, J., McKendich, I.J., Smith, A.N., Knight, H.I., Meller, D.J., Woolhouse, M.E., Gunn, G.J. and Low, J.C. (2006) Prevalence and Virulence Factors of Escherichia coli Serogroups O26, O103, O111 and O145 Shed by Cattle in Scotland. Applied and Environmental Microbiology, 72, 653-659. http://dx.doi.org/10.1128/AEM.72.1.653-659.2006

[23] Joris, M.A., Pierard, D. and DeZulter, L. (2011) Occurrence and Virulence Patterns of E. coli O26, O103, O111 and O145 in Slaughter Cattle. Veterinary Microbiology, 151, 418-421. http://dx.doi.org/10.1016/j.vetmic.2011.04.003

[24] Ekiri, A.B., Landblom, D., Doelkoff, D., Olet, S., Shelver, W.L. and Khaitsa, M.L. (2004) Isolation and Characterisation of Shiga Toxin Producing Escherichia coli Serogroups O26, O45, O111, O103, O121, O145 and O157 Shed from Range and Feedlot Cattle from Post Weaning to Slaughter. Journal of Food Protection, 7, 1052-1061.

[25] Penington, H. (2010) Escherichia coli O157. The Lancet, 376, 1428-1435. http://dx.doi.org/10.1016/S0140-6736(10)60963-4

[26] Roopnarine, R.R., Ammons, D., Rampersad, J. and Adesiyun, A.A. (2007) Occurrence and Characterization of Verocytotoxigenic Escherichia coli (VTEC) Strains from Dairy farms in Trinidad. Zoonoses and Public Health, 54, 78-85. http://dx.doi.org/10.1111/j.1863-2378.2007.01024.x

[27] Brooks, J.T., Sowers, E.G. and Wells, J.G. (2005) Non-O157 Shiga Toxin-Producing Escherichia coli Infections in the United States, 1983-2002. The Journal of Infectious Diseases, 192, 1422-1429. http://dx.doi.org/10.1086/466536

[28] Bettelheim, K.A. (2007) The Non-O157 Shiga-Toxigenic (Verocytotoxigenic) Escherichia coli; Under-Rated Pathogens. Critical Reviews in Microbiology, 33, 67-87. http://dx.doi.org/10.1080/10408410601172172

[29] Sanz, M.E., Viñas, M.R. and Parma, A.E. (1998) Prevalence of Bovine Verotoxin-Producing Escherichia coli in Argentina. European Journal of Epidemiology, 14, 399-403. 
[30] Mohammad, A., Peiris, J.S.M. and Wijewanta, E.A. (1986) Serotypes of Verocytotoxigenic Escherichia coli Isolated from Cattle and Buffalo Diarrhea. FEMS Microbiology Letters, 35, 261-265.

http://dx.doi.org/10.1111/j.1574-6968.1986.tb01539.x

\section{Submit or recommend next manuscript to SCIRP and we will provide best service for you:}

Accepting pre-submission inquiries through Email, Facebook, Linkedin, Twitter, etc A wide selection of journals (inclusive of 9 subjects, more than 200 journals)

Providing a 24-hour high-quality service

User-friendly online submission system

Fair and swift peer-review system

Efficient typesetting and proofreading procedure

Display of the result of downloads and visits, as well as the number of cited articles

Maximum dissemination of your research work

Submit your manuscript at: http://papersubmission.scirp.org/ 